\title{
Long term trends in the occurrence of nosocomial blood stream infection
}

\author{
Geoffrey Taylor MD FRCPC ${ }^{1,2}$, Maureen Buchanan-Chell BScN ${ }^{1}$, Teresa Kirkland BScN ${ }^{1}$, \\ Margaret McKenzie BScN ${ }^{1}$, Rhoda Wiens $\mathrm{BScN}^{1}$
}

G Taylor, M Buchanan-Chell, T Kirkland, M McKenzie, R Wiens. Long term trends in the occurrence of nosocomial
blood stream infection. Can J Infect Dis 2000;11(1):29-33.

OBJECTIVE: To determine trends in the occurrence of nosocomial blood stream infection at the University of Alberta Hospital.

METHODS: A prospective survey of nosocomial blood stream infection was conducted; cases from August 1986 to December 1996 were reviewed. Cases were detected by a review of positive blood cultures reported by the microbiology laboratory. Centers for Disease Control and Prevention definitions of nosocomial infection were used to categorize isolates as nosocomial, community acquired or contaminant.

RESULTS: There were 2389 cases; primary bacteremia was the most common source (57\%), followed by urinary tract, respiratory tract and surgical site sources $(10 \% \mathrm{each})$. The nosocomial blood steam infection rate rose progressively from 6.0/1000 admissions and 4.59/10,000 patient days in 1986 to $11.2 / 1000$ admissions and 14.31/10,000 days in 1996 $(\mathrm{P}<0.01) ; 48 \%$ of the total increase in rate occurred between 1995 and 1996. Significant increases occurred between 1986 and 1996 in primary infections (from 3.2 to $7.5 / 1000$ admissions, $\mathrm{P}<0.01$ ) and infections from all secondary sources (from 2.5 to $3.8 / 1000$ admissions, $\mathrm{P}=0.01$ ). Coagulase-negative staphylococci $(27 \%)$, Staphylococcus aureus (19\%) and enterococci (9\%) were the most common microbial causes. Aerobic Gram-negative bacilli accounted for $28 \%$ and candida for $6 \%$. Coagulase-negative staphylococci, enterococci and candida all became more prevalent as causes of infection over the study period.

CONCLUSIONS: The nosocomial blood stream infection rate in the hospital has nearly doubled in the past 10 years, largely due to increased primary bacteremia.

Key Words: Bacteremia; Epidemiology; Nosocomial infections

\section{Tendances à long terme des septicémies nosocomiales}

OBJECTIF : Déterminer les tendances quant à la survenue des septicémies nosocomiales au University of Alberta Hospital. MÉTHODES : Une enquête prospective sur la septicémie a été entreprise : les cas enregistrés entre août 1986 et décembre 1996 ont été passés en revue. Ces cas ont été identifiés à partir des résultats positifs d'hémocultures signalés par le laboratoire de microbiologie. On a utilisé les définitions de l'infection nosocomiale que donne le Laboratoire de lutte contre la maladie pour catégoriser les isolats selon qu'il s'agissait d'une contamination nosocomiale ou acquise dans la communauté.

RÉSULTATS : On a dénombré 2389 cas : la bactériémie primaire en a été la source la plus fréquente (57\%), suivie des infections urinaires, des infections respiratoires et des infections opératoires (10\% chacune). Le taux de septicémie a graduellement augmenté, de 6,0/1000 admissions et 4,59/10 000 jours-patients en 1986, à 11,2/1000 admissions et 14,31/10 000 patients en 1996 ( $\mathrm{p}<0,01$ ); 48 \% de l'augmentation totale du taux a été enregistré entre 1995 et 1996. Des

voir page suivante

\footnotetext{
${ }^{1}$ University of Alberta Hospital and ${ }^{2}$ University of Alberta, Edmonton, Alberta

Correspondence and reprints: Dr GD Taylor, 2E4.11 WMC, University of Alberta Hospital, 8440 - 112 Street, Edmonton, Alberta T6G $2 B 7$.

Telephone 780-407-7736,fax 780-407-1737,e-mail geoff.taylor@ualberta.ca

Received for publication May 29, 1998. Accepted March 29, 1999
} 
augmentations significatives ont été enregistrées entre 1986 et 1996 sur le plan des infections primaires (de 3,2 à $7,5 / 1000$ admissions, p 0,01) et des sources secondaires d'infection (de 2,5 à 3,8/1000 admissions, p = 0,01). Les staphylocoques coagulase-négatifs ( $27 \%)$, le staphylocoque doré (19\%) et les entérocoques (9\%) ont été les organismes pathogènes les plus fréquents. Les bacilles aérobies Gram-négatifs représentaient $28 \%$ et Candida $6 \%$. La prévalence des staphylocoques coagulase-négatifs, des entérocoques et de Candida, comme causes de l'infection, a augmenté durant la période de l'étude.

CONCLUSIONS : Le taux de septicémie nosocomiale à l'hôpital a presque doublé en dix ans, principalement en raison d'une augmentation des infections primaires.

$\mathrm{H}$ ospital care has long been associated with development of nosocomial infection. Recently, these infections have been identified as a significant public health problem (1-3). Changes in health care delivery over time, including the increased use of invasive procedures or immunosuppressive therapy in hospitalized patients and, conversely, out of hospital treatment of less seriously ill patients has likely changed the frequency and pattern of nosocomial infections. However, it has been difficult to document trends in the occurrence of all nosocomial infections, given the difficulty of capturing such data and the limited immediate benefit of doing so. Nosocomial infections associated with blood stream infection account for less than $10 \%$ of the total, but may result in greater attributable mortality, prolonged length of hospitalization and a higher cost of care than other infections (3-6). Furthermore, such infections are much easier to detect in a prospective surveillance system. Changes in the occurrence of nosocomial blood stream infections may, therefore, provide easily obtainable data which can be used as a surrogate for changes in all nosocomial infections.

Since August 1986, blood culture reports have been prospectively monitored at University of Alberta Hospital to determine the occurrence of nosocomial bloodstream infection. Studies of organ system infections resulting in bloodstream infection and specific microorganisms causing those infections have been reported (7-9). The present study examines all sources, microbiological etiology and long term trends in the frequency of nosocomial bloodstream infection from August 1 , 1986 to December 31, 1996.

\section{METHODS}

The University of Alberta Hospital is a tertiary acute care facility and principal teaching hospital of the University of Alberta Faculty of Medicine. All forms of acute medical care were provided during most of the survey period, including adult and paediatric medicine and surgery, obstetrics/gynecology, hematological oncology, and solid organ transplantation. The hospital has seven intensive care units (ICUs) for critically ill patients: cardiac, adult medical surgical, cardiac surgery, burns, neurosurgery, pediatric and neonatal. In 1995, as part of health care reorganization in the region, all inpatient obstetrics/gynecology, and ophthalmology were transferred to another facility, and increased services were created for intensive care, neurosurgery and cardiac surgery. In 1986, at the beginning of the survey, there were approximately 1200 inpatients beds. Through the study period, there was a gradual reduction in bed number, reaching 1000 in 1992, followed by an abrupt decline from 1992 to 1994, stabilizing at about 600 .
Average admissions remained stable at about 2500 /month between 1986 and 1993. Beginning in 1994, a gradual decline in admissions occurred, to 1980 per month in 1996. Annual blood culture specimens processed by the hospitals clinical microbiology laboratory remained stable through the study period $(10,000$ to 12,000 specimens per year, R Rennie, personal communication).

Other than in ICUs, where phlebotomy was performed by registered nurses, blood cultures were obtained by physicians. Blood cultures were typically performed in sets of two, and incubated aerobically and anaerobically for five to seven days (unless prolonged incubation was requested). Blood cultures reported as growing microorganisms were reviewed daily by nurse practitioners in the hospital's Infection Control program. Patient charts were reviewed. The isolate was classified as a contaminant or as resulting from community-acquired or nosocomial infection based on Centers for Disease Control and Prevention (CDC) criteria (10). When an organism isolated from blood culture was compatible with a nosocomial infection at another site, the blood stream infection was classified as secondary to that other infection. Other isolates, including all intravascular device related infections were classified as primary. When the isolate was an organism that was normal skin flora (eg, coagulase negative staphylococci, Bacillus species, Propionibacterium species), it was considered significant if there were clinical symptoms present, and either the organism was isolated from at least two separate blood cultures or a physician instituted appropriate antimicrobial therapy. The source of secondary infection was determined by chart review. The service or ward where the patient was located when the signs or symptoms of infection first developed was recorded. All cases included in the database occurring between August 1, 1986 , the initiation of the surveillance program, and December 31, 1996 were reviewed.

Data management and statistical methods: Cases of nosocomial blood stream infection were entered into Automated Infection Control Expert (Infections Control and Prevention Analysts Inc, Austin, Texas), a computer software program designed for nosocomial infection surveillance. Statistical comparison of rates was performed by EPI INFO, version $6.04 \mathrm{~b}$ (CDC, Atlanta, Georgia). $\mathrm{P}<0.05$ was considered significant.

\section{RESULTS}

There were 2389 episodes of nosocomial blood stream infection between August 1, 1986 and December 31, 1996. The annual number of cases gradually rose from 184 in 1987, the first full year of the survey, to 267 in 1996 . The case rate similarly rose from $6.0 / 10,000$ admissions in 1986 to $8.7 / 10,000$ 


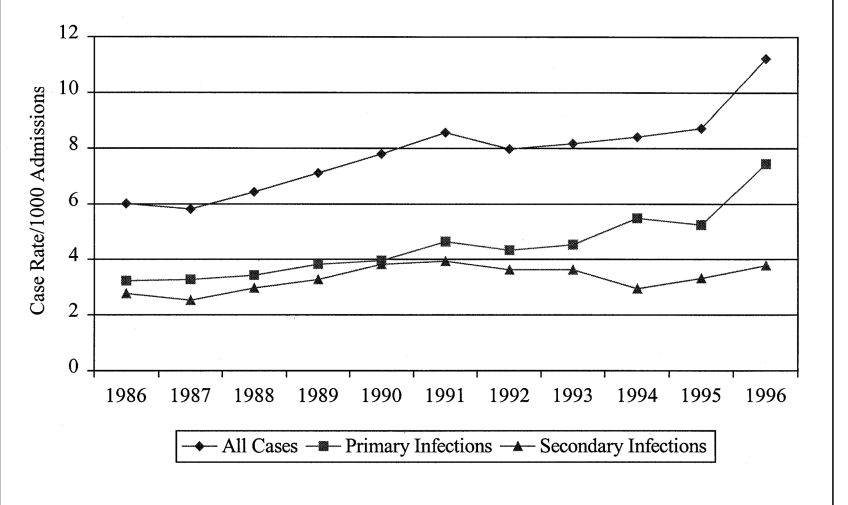

Figure 1) Annual case rate by source of nosocomial blood stream infection, University of Alberta Hospital, 1986 to 1996

\section{TABLE 1}

Sources of infection of nosocomial blood stream infection, University of Alberta Hospital, 1986 to 1996

\begin{tabular}{lc}
\hline Source & $\begin{array}{c}\text { Number of episodes of blood } \\
\text { stream infection (\%) }\end{array}$ \\
\hline Primary & $1362(57.0)$ \\
Urinary tract & $248(10.4)$ \\
Respiratory tract & $237(9.9)$ \\
Surgical site & $228(9.5)$ \\
Gastrointestinal tract & $176(7.4)$ \\
Skin/burn & $102(4.3)$ \\
Female genital tract & $14(0.6)$ \\
Other & $22(0.9)$ \\
Total & $2389(100)$ \\
\hline
\end{tabular}

admissions in 1995 (Figure 1), and abruptly rose to $11.3 / 10,000$ admissions in 1996 (risk ratio [RR] 1.9, 95\% CI 1.4 to 2.4 compared with 1986 ; RR $1.29,95 \%$ CI 1.08 to 1.54 compared with 1995). The nosocomial blood stream infection rate for the entire period was $7.8 / 10,000$ admissions. Using patient days as a denominator, the case rate increased from 4.59/10,000 patient days in 1986 to 14.31 in 1996 (RR 3.1, $95 \%$ CI 2.4 to 4.1 .

Sources of infection: Table 1 presents the sources of infection for 2389 cases. Primary infection, largely resulting from infection of intravascular devices, was by far the most common source, accounting for $57 \%$ of the total. Urinary tract, respiratory tract and surgical site infections with secondary blood stream infection were a tightly clustered second group of sources, each accounting for about $10 \%$ of the total. Primary infection increased in frequency from 3.3/1000 admissions in 1986 to $7.5 / 1000$ in 1996 (relative risk $2.3,95 \%$ CI 1.6 to 3.2 compared with 1986; $\mathrm{P}<0.01)$. There was an abrupt increase between 1995 and 1996 (relative risk 1.4, 95\% CI 1.1 to 1.8; $\mathrm{P}<0.01$ ). While no other source of infection significantly increased in frequency, all secondary sources as a group increased from 2.5/1000 in 1986 to 3.8/1000 in 1996 (relative risk $1.5,95 \% \mathrm{Cl} 1.1$ to $2.1 ; \mathrm{P}=0.01$ ).

Microbial etiology: A total of 2582 different microbial species were identified in the 2389 cases (Table 2). Aerobic Gram-
TABLE 2

Nosocomial blood stream infection, University of Alberta Hospital, 1986 to 1996

\begin{tabular}{lc}
\hline Pathogen & Number of isolates (\%) \\
\hline Aerobic Gram-negative bacteria & \\
Enterobacteriaceae & \\
Escherichia coli & $233(9.0)$ \\
Klebsiella species & $146(5.6)$ \\
Enterobacter species & $99(3.8)$ \\
Serratia species & $39(1.5)$ \\
Other & 36 \\
Subtotal & $533(21.5)$ \\
Non-Enterobacteriaceae & \\
Pseduomonas species & $114(4.4)$ \\
Acinetobacter species & $14(0.5)$ \\
Haemophilus species & $12(0.5)$ \\
Stenotrophomonas species & $10(0.4)$ \\
Other & 19 \\
Subtotal & $168(6.5)$ \\
Subtotal aerobic Gram-negative bacteria & $723(28.0)$ \\
Aerobic Gram-positive bacteria & \\
Bacilli & $24(0.9)$ \\
Cocci & \\
Coagulase-negative staphylococcus & $686(26.6)$ \\
Staphylococcus aureus & $476(18.5)$ \\
Enterococcus species & $235(9.1)$ \\
Streptococcus species & $168(6.5)$ \\
Subtotal & $1573(61.1)$ \\
Anaerobic bacteria & \\
Bacteroides species & $48(1.9)$ \\
Other & 32 \\
Subtotal & $17(0.1)$ \\
Other bacteria & \\
Yeast and fungi & \\
Candida species & \\
Other & \\
Subtotal & $(6.4)$ \\
Total & \\
\hline
\end{tabular}

positive cocci as a group were most common (61.1\%). As the authors have previously reported (7), aerobic Gram-negative bacilli were less common, accounting for $28 \%$ of infections. Yeast and fungi infections were uncommon (6.9\%), and were almost entirely caused by Candida species. Anaerobic bacteria were relatively rare causes of nosocomial blood stream infection $(3.1 \%)$.

Only three groups of microorganisms increased in prevalence as a cause of infection between 1986 and 1996: coagulase-negative Staphylococcus species, Enterococcus species and Candida species (Figure 2). The number and case rate for coagulase-negative Staphylococcus species increased nearly every year between 1988 (46 cases, 14.4/10,000 admissions) and 1996 (82 cases, 34.5/10,000 admissions) (RR 2.5 compared with $1988,95 \% \mathrm{CI} 1.5$ to 4.3 ). The number and case rate for the Enterococcus species remained relatively stable between 1986 (5.5/1000 admissions) and 1995 (8.1/1000 admissions), but then both significantly increased in 1996 to 19.8/10,000 admissions (RR 2.4 compared to $1986,95 \%$ CI 1.5 


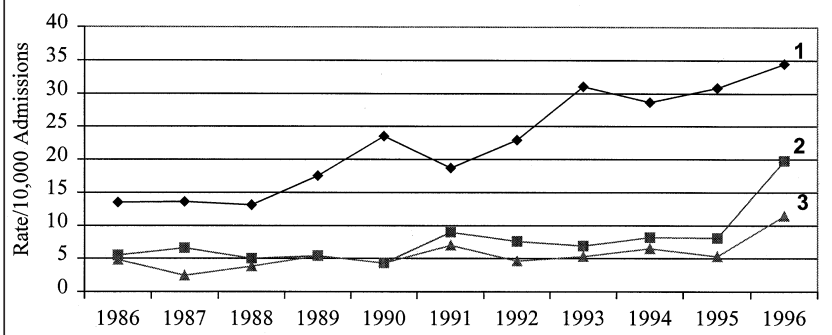

$\rightarrow-$ Coagulase Negative Staphylococci $\rightarrow$ Enterococci $\rightarrow$ Candida

Figure 2) Case rate for selected microorganisms causing nosocomial blood stream infections, University of Alberta Hospital, 1986 to 1996. 1 Risk ratio (RR) 2.56(1.52 to 4.31) compared with 1986; 2 RR 2.44 (1.45 to 4.11 compared with 1995); 3 RR 2.16 (1.11 to 4.18 compared with 1995)

to 4.1). Similarly, the number and case rate of Candidemia remained stable from 1986 (4.8/1000 admissions) and 1995 $(5.3 / 1000)$ but then increased to $11.4 / 1000$ in 1996, RR 2.2 compared with $1986,95 \%$ CI 1.1 to 4.2 . As previously reported (11), the species responsible for candidemia remained unchanged throughout the survey period. No other microbial species or group (eg, aerobic Gram-negative bacteria, anaerobic bacteria) significantly changed in annual incidence.

There were 233 (9.8\%) episodes in which more than one organism was identified (polymicrobial bacteremia). Polymicrobial cases were more likely to be secondary to skin or burn wound infection $(8.6 \%)$, or of gastrointestinal source $(15.1 \%$, $\mathrm{P}=0.01)$, and were less likely to be primary $(49.6 \%, \mathrm{P}=0.01)$ or from a surgical site source $(4.3 \%, \mathrm{P}<0.01)$ than monomicrobial infections.

\section{DISCUSSION}

Our survey demonstrates that the risk of nosocomial blood stream infections has nearly doubled for patients admitted to our hospital between 1986 and 1996, as a result of small but relentless increases from 1986 to 1995 , followed by a large increase between 1995 and 1996. Because our surveillance technique, definitions of infection and number of blood culture specimens tested did not change we believe this is a real increase in rate. Some of this increased rate may be only relative. Hospital 'downsizing' has likely resulted in the out of hospital treatment of less seriously ill patients, resulting in a residual patient pool with an increased severity of illness $(12,13)$. Despite downsizing, the actual number of nosocomial blood stream infections occurring annually in our hospital has increased, indicating that there has been an absolute as well as relative increase in risk of infection. While changes in frequency of nosocomial blood stream infections may not be directly translatable to all nosocomial infections, these data suggest that nosocomial infections may have generally increased in frequency, because secondary blood stream infections as a group also increased in frequency.

Our data parallel the long term trends reported from American hospitals $(5,14,15)$, but there are some important distinc- tions. Pittet et al (14) reported that between 1981 and 1992 at the University of Iowa Hospital nosocomial blood stream infections increased from $6.7 / 1000$ admissions to $18.4 / 1000$ admissions compared with our average rate of $7.8 / 1000$ and 1996 rate of $11.3 / 1000$. They also demonstrated a linear increase in rate throughout the 12 survey years, both overall and for a range of specific pathogens. Our experience differs in that a slow rate of rise was seen for only coagulase-negative staphylococcal infections followed by a sudden increase in a range of pathogens in 1996. These distinctions imply that the determinants of baseline and increases in frequency of nosocomial infections, including blood stream infection, are not evenly applied among institutions, and provide justification for the collection of local as well as Canadian data, rather than simply extrapolating from the American experience. The sudden increase that our hospital experienced in 1996 occurred after extensive restructuring of health care delivery in 1995. This occurrence will be the subject of a more in-depth study.

Our data highlight the important and growing role of intravascular devices as a source of nosocomial blood stream infections (5). Over half of all the infections were attributable to a primary source, largely associated with intravascular devices. Further, the annual rate of these infections increased by $129 \%$ between 1987 and 1996, compared with a 52\% increase in annual rate for all secondary sources; by $1996,67 \%$ of all blood stream infections were primary. There is an urgent need for research into and the implementation of techniques to prevent central venous catheter infections, the most common cause of primary infections (16-19).

\section{CONCLUSIONS}

Between 1986 and 1996, the rate of nosocomial blood stream infections in patients admitted to our hospital nearly doubled. This increase comprised of two patterns: a slow increase from 1986 to 1995, associated predominantly with coagulase-negative staphylococcal infections and primary sources, and a dramatic rise between 1995 and 1996 associated with a range of pathogens.

\section{REFERENCES}

1. Haley RW, Culvert DH, White JAW, Moorage WM, Emori TG. The nationwide nosocomial infection rate. A need for a new vital statistic. Am J Epidemic 1985;121:159-67.

2. Public Health focus. Surveillance, prevention, and control of nosocomial infections. MMWR 1992;41:783.

3. Pittet D, Tarara D, Wenzel RP. Nosocomial bloodstream infection in critically ill patients. Excess length of stay, extra costs, and attributable mortality. JAMA 1994;271:1598-601.

4. Wenzel RP. The mortality of hospital-acquired bloodstream infections: need for a new vital statistic? Int J Epidemiol 1988; $17: 225-7$.

5. Banerjee SN, two other authors, et al. Secular trends in nosocomial primary bloodstream infections in the United States, 1980-1989. Am J Med 1991;91(Suppl 3B):86S-9S.

6. Pittet D, Wenzel RP. Nosocomial bloodstream infections. Arch Intern Med 1995;155:1177-84.

7. Taylor GD, Buchanan-Chell M, Kirkland T, McKenzie M, Wiens R. Nosocomial Gram negative bacteremia. Int J Infect Dis 1997;1:202-5.

8. Taylor GD, Buchanan-Chell M, Kirkland T, McKenzie M, Wiens R. Nosocomial urosepsis: Analysis of 218 cases. Int J Infect Dis 1996;1:92-4. 
9. Taylor GD, Buchanan-Chell M, Kirkland T, McKenzie M, Wiens R. Bacteremic nosocomial pneumonia: A 7-year experience in one institution. Chest 1995;108:786-8.

10. Garner JS, Jarvis WR, Emori TG, Horan TC, Hughes JM. CDC definitions for nosocomial infections. Am J Infect Control 1988; $16: 128-40$

11. Taylor GD, Buchanan-Chell M, Kirkland T, McKenzie M, Wiens R. Trends and sources of nosocomial fungaemia. Mycoses 1994;37:187-90.

12. Shamian J, Lightstone EY. Hospital restructuring initiatives in Canada. Med Care 1997;35:OS62-9.

13. Anderson GM. Hospital restructuring and the epidemiology of hospital utilization. Recent experience in Ontario. Med Care 1997;35:S93-OS101.

14. Pittet D, Wenzel RP. Nosocomial bloodstream infections. Secular trends in rates, mortality, and contribution to total hospital deaths. Arch Intern Med 1995; 155:1177-84.

15. Morrison AJ Jr, Freer CV, Searcy MA, Landry SM, Wenzel RP.
Nosocomial bloodstream infections: Secular trends in a statewide surveillance program in Virginia. Infect Control 1986;7:550-3.

16. Raad I, Darouiche R, Dupuis J, et al. Central venous catheters coated with minocycline and rifampin for the prevention of catheter-related colonization and bloodstream infections. A randomized, double-blind trial. Ann Intern Med 1997;127:267-74.

17. Maki DG, Stolz SM, Wheeler S, Mermel LA. Prevention of central venous catheter-related bloodstream infection by use of an antiseptic-impregnated catheter. A randomized, controlled trial. Ann Intern Med 1997;127:257-66.

18. Darouiche RO, Raad I, Heard SO, et al. A comparison of two antimicrobial-impregnated central venous catheters. N Engl J Med 1999;340:1-8.

19. Cohen Y, Fosse JP, Karoubi P, et al. The "hands-off" catheter and the prevention of systemic infections associated with pulmonary artery catheter. Am J Respir Crit Care Med 1998; $157: 184-7$.

\section{HIV Protocols, edited by N Michael and JH Kim (1999). Humana Press, 999 Riverview Drive, Suite 208, Totowa, New Jersey, 07512, USA. ISBN 0-89603-369-4; 421 pages; US\$89.50}

HIV Protocols brings together a number of basic science protocols as applied to different areas of HIV research. It has been divided into four sections, which include: "Virology"; "Molecular Biology"; "Humoral Immunology"; and "Cellular Immunology". The book is part of the Methods in Molecular Medicine series from Humana Press, which advertises that readers will find everything that they need in the book to carry out the procedures, especially with their 'notes' section at the end of each chapter, which lets readers in on all the trade secrets. HIV Protocols will be a good addition to a basic science lab that processes various HIV clinical specimens. Graduate students or clinical fellows starting out on their careers in basic experimental science will find it most useful.

"Virology", the first section of the book, has eight chapters. The first chapter is the most important because it deals with the general method for cultivation of HIV from cells and body fluids of humans infected with HIV. Two chapters look at quantitation of HIV, which includes a general method for running a reverse transcriptase assay. A chapter on the study of viral entry into the cell introduces the use of reporter viruses instead of using live viruses. The remaining chapters in this section focus on different techniques for studying the identification of chemokine receptors, which seems a little out of touch with the earlier chapters.

The second section of the book, entitled "Molecular Biology", is made up of 18 chapters. As with the first section, this one has some chapters with general molecular techniques such as southern blotting, northern blotting and in situ polyermase chain reaction specifically designed with HIV in mind, and then moves to more specific procedures. Five chapters deal with quantitation or cloning of viral RNA or proviral DNA, using both homemade and commercial as- says. Included is a chapter on the cloning of full length copies of the HIV provirus. For those groups involved in epidemiological field research, the two chapters, which employ dried blood and plasma spots on filter paper to identify HIV subtypes and infection status, will be of interest. The remaining chapters take a sharp turn, with techniques to look at HIV promoter activity and expression and an assay to measure telomere length.

"Humoral Immunology" is the third section, made up of 10 chapters. The first two chapters describe general methods for setting up an in-house ELISA and western blotting or immunoblotting assays to identify anti-HIV antibodies. Two chapters on antibody-antigen interaction are not very useful unless the reader happens to have a FACS system or a machine to measure surface plasmon reasonance. However, there is an excellent chapter describing general methods to carry out ELISPOT assays. Two different HIV infection neutralization assays are given and the procedure needed to collect and process human mucosal specimens, which is a bit of a repeat of an earlier chapter. The final chapter describes how to collect every possible specimen from all mucosal sites in a mouse, making it very applicable to research other than with HIV.

Seven chapters make up the final section entitled "Cellular Immunology". The topics covered here include lymphocyte proliferation assays, cytotoxic T-cell assays, measurement of antibody-dependent cellular cytotoxicity and detection of apoptosis, which are all important techniques in HIV research.

Overall, this book has compiled a number of general basic science protocols in the fields of virology, molecular biology and immunology as applied to the study of HIV. The thorough nature of the materials and methods section of each chapter ensures that the reader will get off to a good start when using these techniques in their own lab.

Ian McLean

Department of Medical Microbiology

University of Manitoba Winnipeg, Manitoba 


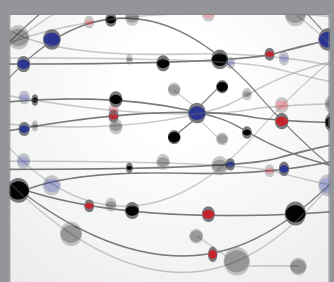

The Scientific World Journal
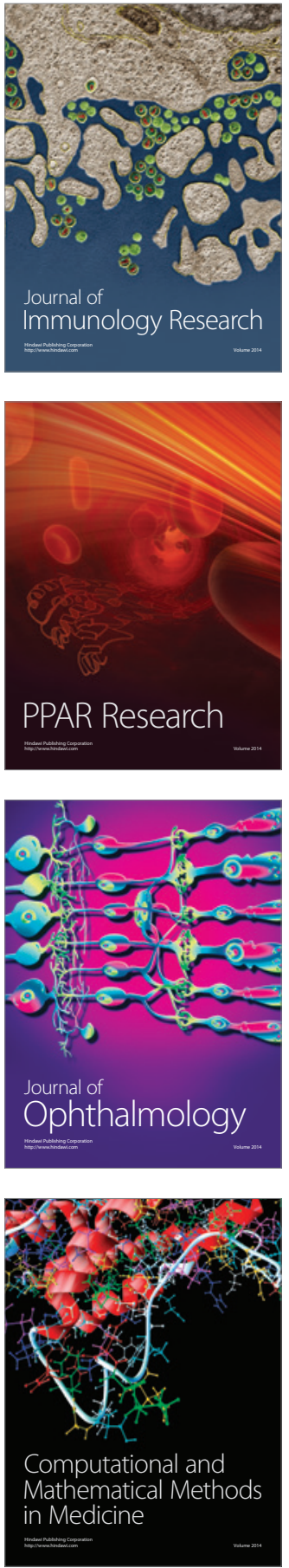

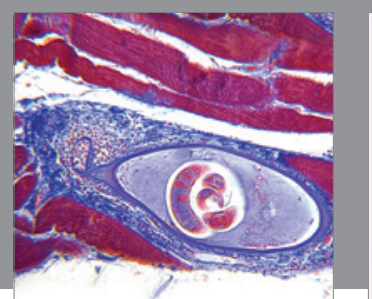

Gastroenterology Research and Practice

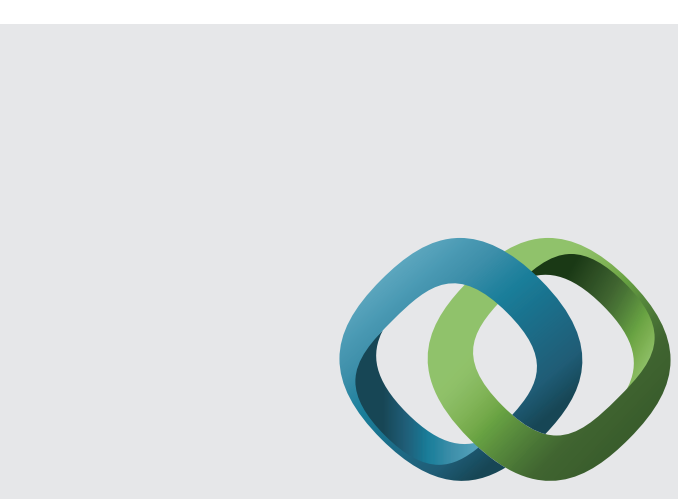

\section{Hindawi}

Submit your manuscripts at

http://www.hindawi.com
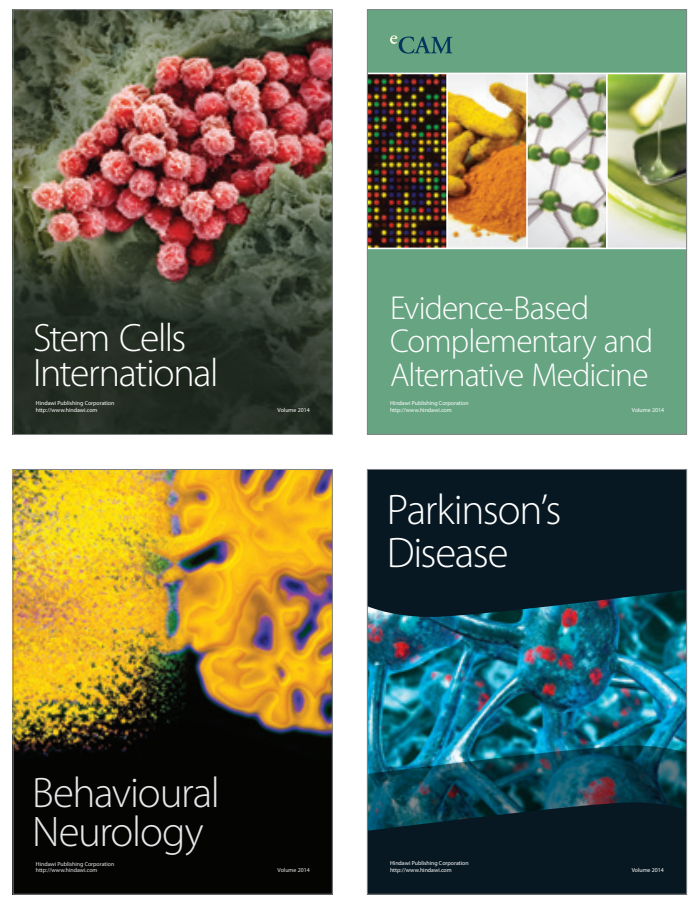
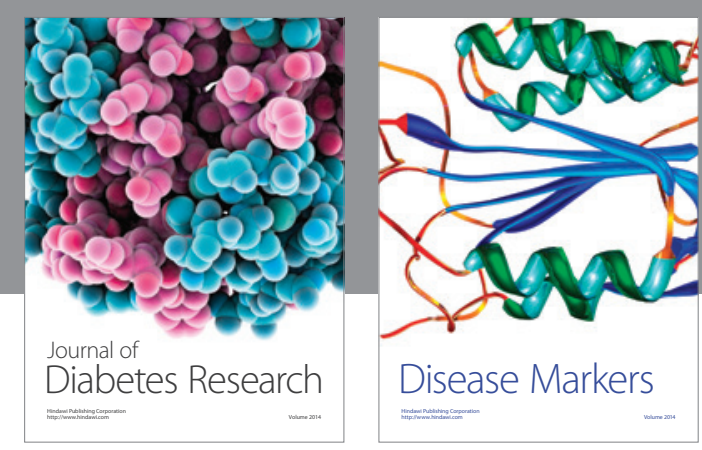

Disease Markers
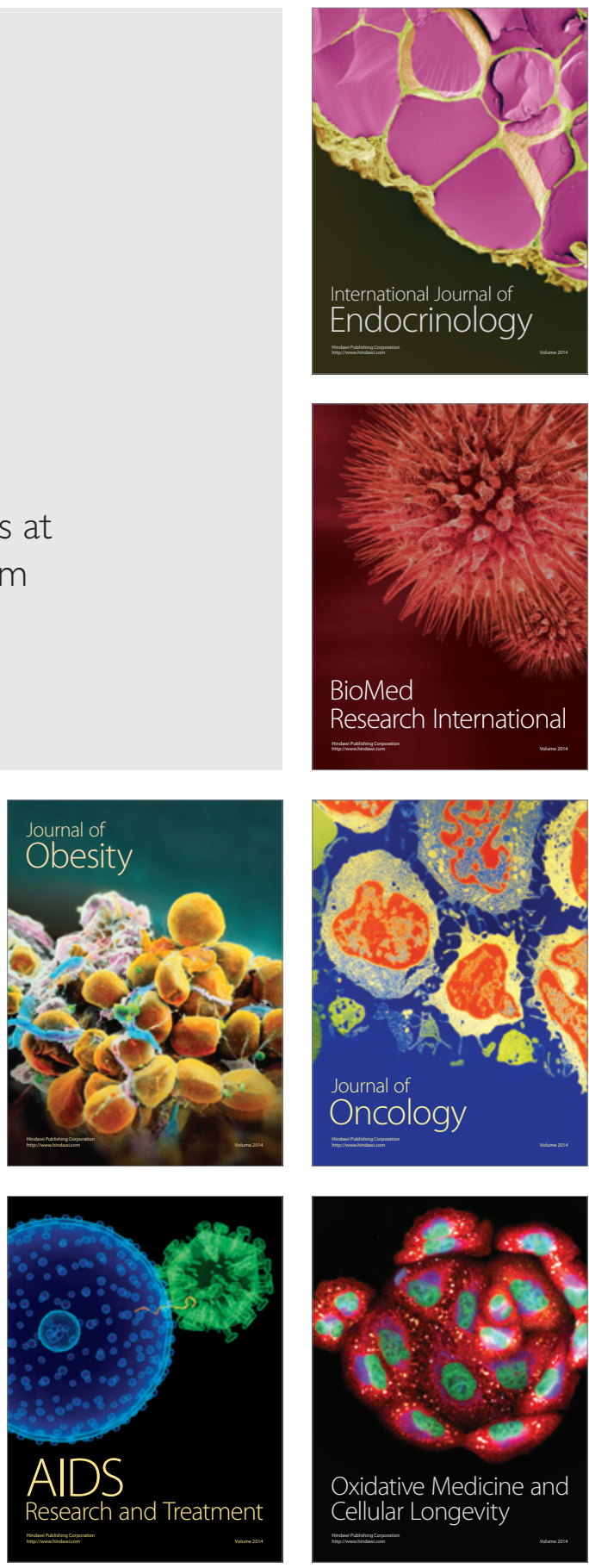